\title{
A novel porphyrazine ligand tailored to homogeneous metal catalyzed transformations
}

\author{
Matteo Parravicini, ${ }^{a}$ Luca Vaghi, ${ }^{\mathrm{b}}$ Giancarlo Cravotto, ${ }^{\mathrm{c}}$ Norberto Masciocchi, ${ }^{\mathrm{b}}$ Angelo \\ Maspero, ${ }^{\mathrm{b}}$ Giovanni Palmisano, ${ }^{\mathrm{b}}$ and Andrea Penoni ${ }^{\mathrm{b} *}$ \\ ${ }^{a}$ Dipartimento di Scienza dei Materiali, Università degli Studi di Milano Bicocca, 20126 Milano, \\ Italy \\ ${ }^{b}$ Dipartimento di Scienza e Alta Tecnologia, Università degli Studi dell'Insubria, 22100 Como, \\ Italy \\ ${ }^{c}$ Dipartimento di Scienza e Tecnologia del Farmaco, Università degli studi di Torino, 10125 \\ Torino, Italy \\ E-mail: andrea.penoni@uninsubria.it
}

DOI: $\underline{\text { http://dx.doi.org/10.3998/ark.5550190.p008.813 }}$

\begin{abstract}
A novel centrosymmetric porphyrazine $(\mathrm{Pz}) \mathbf{1}$ decorated with pyrazino-dibenzo[ $b, f]$ azepine units have been prepared via Linstead macrocyclization reaction of a dinitrile precursor. Accordingly, the peripheral azepine nitrogen offers a chemical handle for subsequent functionalizations. Characterization of the metal complexes (MPzs = Metal Porphyrazines) of $\mathbf{1}$ was accomplished and good catalytic performances were achieved in the $\mathrm{Cu}(\mathrm{II})-$ and $\mathrm{Co}(\mathrm{II})-$ catalyzed cyclopropanation with ethyl diazoacetate as a test reaction.
\end{abstract}

Keywords: Porphyrazine, oxcarbazepine, heterocycles, macrocycles, homogeneous catalysis, cyclopropanation

\section{Introduction}

Phthalocyanines (Pcs) are $D_{4 \mathrm{~h}}$ symmetry (due to mesomeric averaging as metal complexes, dications or dianions) macrocyclic compounds with aromatic $18 \pi$ - electrons, closely related to the natural occurring porphyrins. As porphyrins they could host a variety of metal ions inside the central cavity of the system. Pcs per se and their metal Pcs (MPCs) offer a wide assortment of extensively functionalized structures with classical application as pigments and dyes and, more recently, in photodynamic therapy, as photonic materials (e.g. mesogenics, NLO, optomaterials) and functionalized solids (e.g. microporous solids, conductive polymers, ferroelectrics, chemical sensors). ${ }^{1-4}$ 
In addition to the above mentioned applications, Pcs had found place as ligands in a wide number of metal catalyzed organic transformations (e.g. oxidation, synthesis of nitrogencontaining compounds, $\mathrm{C}-\mathrm{C}$ bond formation, reduction and many other useful synthetic procedures). ${ }^{5}$ The application of MPcs as catalysts is an emerging strategy and has attracted broad interests due to their accessibility in terms of the cost and straightforward preparation on a large scale as well as their chemical and thermal stability. Porphyrazines (Pzs) represent a structural analogue of porphyrines in which the meso carbons of porphyrines are replaced with $\mathrm{N}$ atoms. This structural similarity would make Pzs a good candidate for development of functional dyes, molecular devices and biomedical applications. A peculiar styudy on porphyrazines and related metal complexes was reported by Ercolani and coworkers. ${ }^{6}$ Recently, Pzs has attracted a lot of attention for their intense electronic absorption and emission in their near infrared region. Homogeneous and heterogeneous catalysis with metal porphyrazines (MPzs) has been extensively demonstrated, also their use as biomimetic catalyst was successfully achieved. ${ }^{7}$ However, for some of these applications, MPzs are of disappointing use due to their scarce solubility in common organic solvents and this drawback could be overcome by an appropriate decoration of the periphery of the macrocycle. ${ }^{8}$

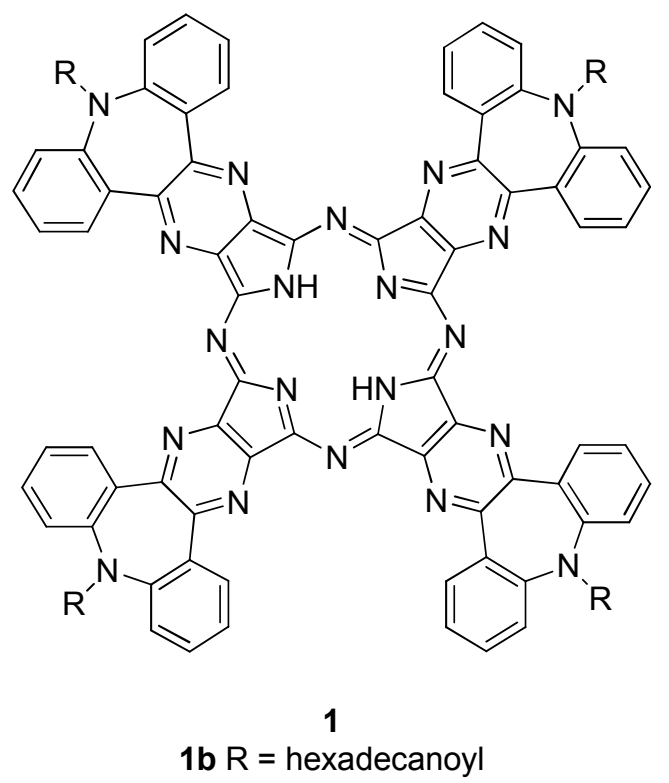

\section{Figure 1}

In this paper we report the synthesis of a novel centrosymmetric Pz system (Figure 1), arising from the formal substitution of four benzo subunits in a Pc by a $9 H$-dibenzo[b,f]pyrazino[2,3- $d]$ azepine moiety, wherein the peripheral azepine nitrogen atoms offer a chemical handle for subsequent functionalizations (i.e., introduction of lipophilic chains in order to address the above issue as in 1b). Accordingly, cyclopropanation with ethyl diazoacetate (EDA) catalyzed by the $\mathrm{Cu}(\mathrm{II})$ - and $\mathrm{Co}(\mathrm{II})$-metal complexes $\mathbf{1 1}$ and $\mathbf{1 2}$, 
respectively, of the highly lipophilic $N$-hexadecanoyl porphyrazine $\mathbf{1 b}$ is also reported as test reaction.

\section{Results and Discussion}

There are a number of protocols available for synthesis of porphyrazine macrocycles and, of the particular relevance to our work, were methods based on tetramerization of ortho-disubstituted arenes (i.e., phthalic acids and anhydrides, phthalimides, diiminoisoindolines, $o$ cyanobenzamides). ${ }^{9}$ Retrosynthetic analysis suggested to pick the $5 H$-dibenzo $[b, f]$ azepine- 10,11 dione 3 as key intermediate, due to the potential of supplying the required $o$-dinitrile $\mathbf{4}$ through a $[4+2(\mathrm{CC}+\mathrm{NCCN})]$ cyclocondensation with diaminomaleonitrile as 1,4-bis(nucleophile) (Scheme 1).<smiles>N#Cc1nc2c(nc1C#N)-c1ccccc1Nc1ccccc1-2</smiles><smiles>O=c1c2ccccc2[nH]c2ccccc12</smiles><smiles>NC(=O)N1c2ccccc2CC(=O)c2ccccc21</smiles>

\section{Scheme 1}

With ample supply of oxcarbazepine 2 available, our intention was to effect a one-pot tandem oxidation $/ \mathrm{N}$-decarbamoylation to yield diketone $\mathbf{3}$ required for the elaboration of porphyrazine ring system (Scheme 2). We initially considered application of a report by Heckendorn describing the transformation of $\mathbf{2}$ into $\mathbf{3}$ by a multi-step procedure, entailing $\alpha$-carbonyl bromination of $\mathbf{2}$, nucleophilic substitution with KOAc followed by aerial oxidation. ${ }^{10}$ In our hands, however, yields of $\mathbf{3}$ remain unsatisfactory, notwithstanding strict adherence to conditions prescribed by Heckendorn. Therefore, we attempted to design a method that would enhance the yields and, possibly, through a shorter synthetic pathway. Several methods currently exist to obtain $\alpha$-diketones by oxidation of $\alpha$-methylene ketones. Among these are the use of venerable $\mathrm{SeO}_{2}$ (Riley method), ${ }^{11}$ seleninic acids and anhydrides, pyridinium chlorochromate (PCC) or $\mathrm{KMnO}_{4}$ as oxidant agents. Multi-step approaches have also been reported like Kornblum oxidation of $\alpha$-bromo ketones, nitrosation, microwave promoted oxidation or $\mathrm{CuBr}_{2}$ adsorbed on alumina. ${ }^{12}$

Each method has its advantage and drawbacks in any given situation. For the sake of expediency, we opted for an oxidant able to gain $\mathbf{3}$ from $\mathbf{2}$ in only one step. Thus, a survey of oxidants was undertaken and on treatment of 2 with freshly sublimed $\mathrm{SeO}_{2}$ (2.5 equiv) in refluxing 1,4-dioxane for $7 \mathrm{~h}$, clean tandem oxidation/ $N$-decarbamoylation pleasingly ensued to produce 3 in $90 \%$ yield. $^{13,14}$ This compound precipitates directly from the reaction mixture as 
orange solid so that this process proved useful enough to prepare multigram quantities of $\mathbf{3}$. The mechanism of $N$-decarbamoylation is not clear at this time, but it seems plausible that reaction may commence with nucleophilic attack of amide carbonyl (as carboximidic acid tautomer) on $\mathrm{SeO}_{2}$, followed by proton transfer with formation of a $\mathrm{N}$-cyano intermediate and seleninic acid. The subsequent hydrolysis of the former would result in $\mathbf{3}^{15,16}$

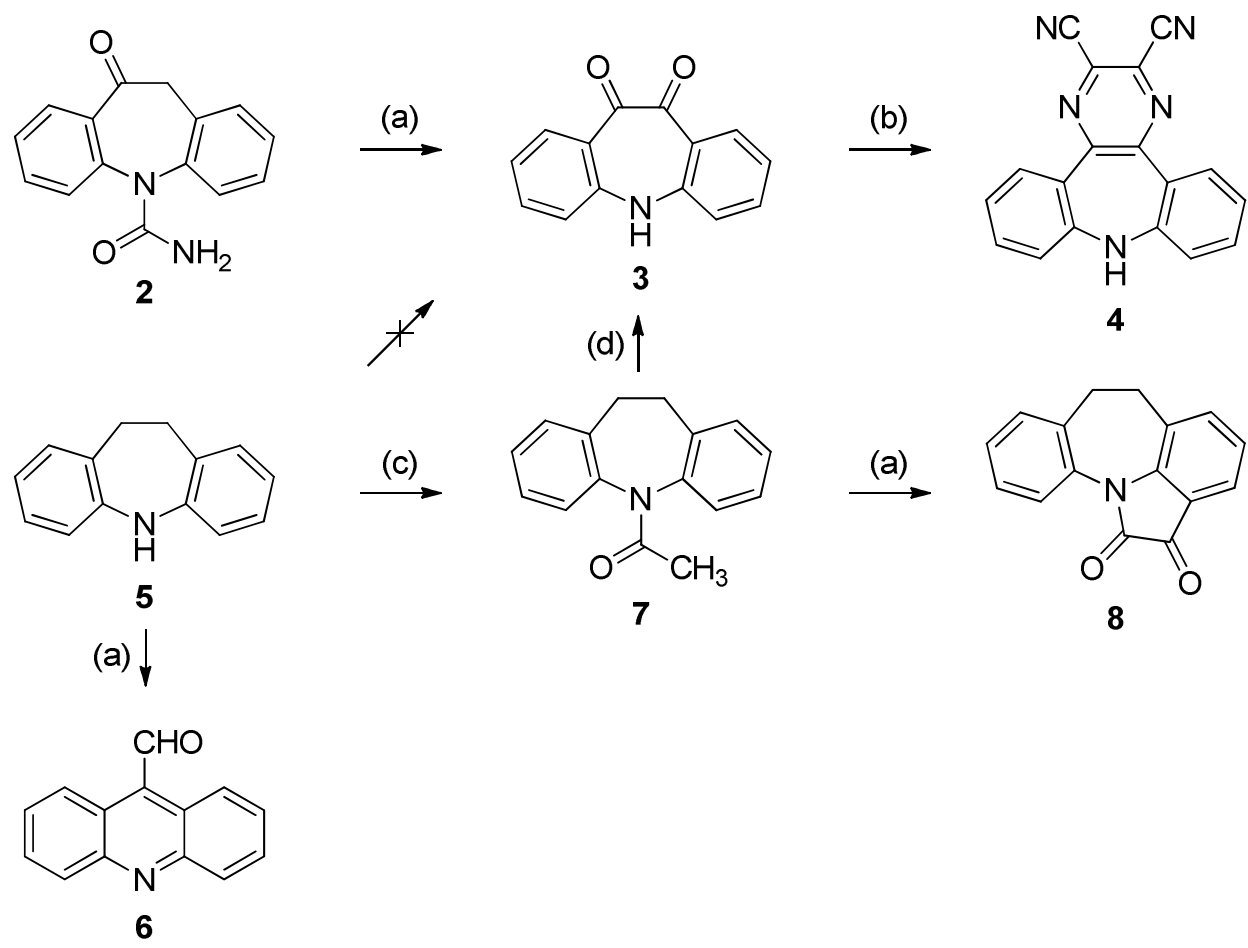

Scheme 2. Reagents and conditions: (a) $\mathrm{SeO}_{2}$, 1,4-dioxane, reflux, $7 \mathrm{~h}$; (b) diaminomaleonitrile, $\mathrm{AcOH}$, reflux, $1 \mathrm{~h}$; (c) $\mathrm{Ac}_{2} \mathrm{O}$, reflux 3 h; (d) $\mathrm{BSA}, \mathrm{PhCl}$, reflux, 8 h.

In the approach to $\mathbf{3}$, alternatives to Scheme 2 were examined which proved less successful or less direct. Chen and coworkers reported a three-step procedure from iminostilbene (5H-dibenzo[ $b, f]$ azepine) concerning a progressive oxidation of the bridged double bond within an acceptable overall yield of $43 \% .{ }^{17}$ We checked the possibility to obtain $\mathbf{3}$ from commercially available 10,11-dihydro-5H-dibenzo[ $b, f]$ azepine 5. Unfortunately, our initial efforts on this proved to be less straightforward than expected. For instance, use of either $\mathrm{SeO}_{2}$ or benzeneseleninic anhydride under conditions identical to those used with $\mathbf{3}$ proved fruitless because of various side products including the aldehyde $\mathbf{6}$ (formed by tandem benzylic rearrangement/ oxidative decarboxylation), presumably as a consequence of the unprotected $\mathrm{NH}$. The susceptibility of dibenzazepines toward ring contraction to give acridine derivatives is well documented. ${ }^{18-20}$ Thus, reaction of 5 with refluxing $\mathrm{Ac}_{2} \mathrm{O}(3 \mathrm{~h})$ gave $7^{21}$ which was converted to 3 in $67 \%$ overall yield, upon exposure to benzeneseleninic anhydride (BSA) (2 equiv) in chlorobenzene at $120{ }^{\circ} \mathrm{C} .{ }^{22}$ In stark contrast, access to $\mathbf{3}$ from $\mathbf{5}$ with $\mathrm{SeO}_{2}$ in refluxing dioxane 
was messy and resulted in a complex mixture of compounds from which the isatin derivative $\mathbf{8}^{23}$ was isolated, albeit in abysmally low yield. The structure of $\mathbf{8}$ has been established by singlecrystal X-ray crystallography (Figure 2).

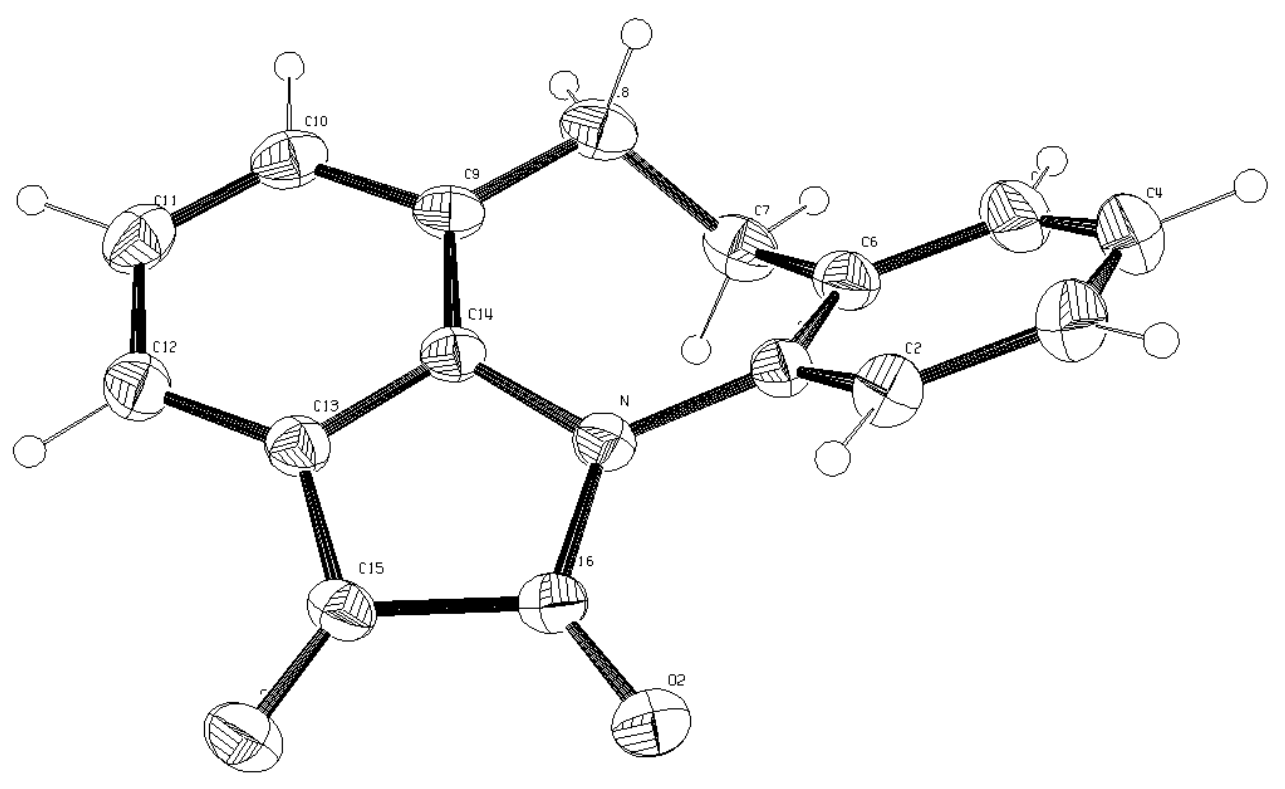

Figure 2. ORTEP drawing of the molecular structure of compound 8, with thermal ellipsoids drawn at the $30 \%$ probability level. For sake of clarity, $\mathrm{H}$ atoms have been drawn as circles of arbitrary radius.

At this point, to get ready for Linstead macrocyclization step, ${ }^{24}$ we only needed to react the 1,2-diketone 3 with diaminomaleonitrile as 1,4-bis(nucleophile) to form the required $o$ dinitrile 4 (Scheme 3), an operation which succeeded readily by refluxing the mixture in $\mathrm{AcOH}$ (1 h) $(65 \%$ yield $)$.

En route to porphyrazine, we were forced to postpone the tetramerization process of $\mathbf{4}$ owing to its poor solubility, which has hampered the purification. Thus, attempts were made to improve the solubility by incorporation of a long alkyl chain at the azepine $N$ atom. After sampling a variety of derivatives (amides and tertiary $N$-alkyl amines), the hexadecanoyl group (i.e., 9) appeared to be optimal in terms of yield and lipophilicity. Acylation of $\mathbf{4}$ was performed in anhydrous pyridine at $100{ }^{\circ} \mathrm{C}$ with hexadecanoyl chloride (1.1 equiv) in the presence of a catalytic amount of 4-N,N-dimethylaminopyridine (DMAP) and resulted in the isolation of 9 in $77 \%$ yield (Scheme 3). Finally, compound 9 was converted into its porphyrazine magnesium complex 10 via Linstead's $\mathrm{Mg}$ template cyclization. Therefore, $\operatorname{Mg}(n-\mathrm{BuO})_{2}$ was prepared by heating $\mathrm{Mg}$ in 1-butanol for $6 \mathrm{~h}$ after which the dinitrile 9 was added and the reaction was 
allowed to run under reflux for $8 \mathrm{~h}$. After silica gel chromatography the magnesium complex $\mathbf{1 0}$ was isolated in $32 \%$ yield as a dark green powder.

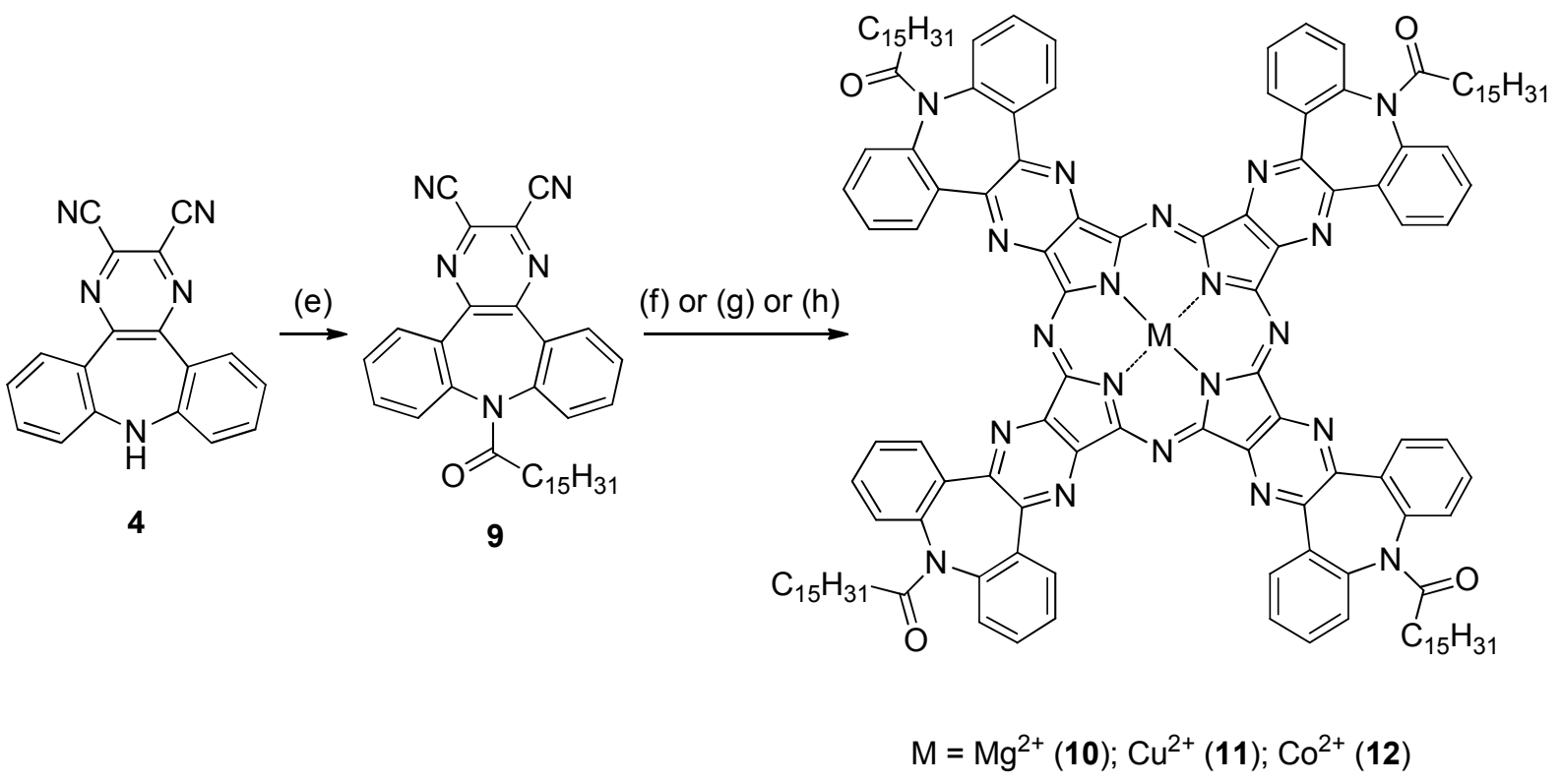

Scheme 3. Reagents and conditions: (e) palmitoyl chloride , pyridine, reflux, 6h; (f) 1) $\mathrm{Mg}, \mathrm{I}_{2}$, n-BuOH, reflux 6 h N2, 2) 9, reflux 8 h; (g) $\mathrm{Cu}(\mathrm{OAc})_{2}$, DMAE, DBU, MW 350W 10 min; (h) $\mathrm{Co}(\mathrm{OAc})_{2}$, DMAE, DBU, MW 350W $10 \mathrm{~min}$.

With 10 in hand, the conversion into the respective $\mathrm{Cu}$ (II) and Co(II) complexes, $\mathbf{1 1}$ and 12, was undertaken by well-known transmetallation procedure. ${ }^{9}$ Treatment of $\mathbf{1 0}$ with a variety of Bronsted acids (e.g., TFA, AcOH, $\mathrm{H}_{2} \mathrm{SO}_{4}$ ) followed by subsequent remetallation with either $\mathrm{Cu}(\mathrm{OAc})_{2}$ or $\mathrm{Co}(\mathrm{OAc})_{2}$ uniformly resulted in formation of a reaction mixture in which only small quantities of the expected $\mathbf{1 1}$ and 12, respectively, could be isolated. At this juncture, we turned our attention to Linstead's metal template strategy. Gratifyingly, when $\mathbf{9}$ was irradiated for $10 \mathrm{~min}$ in a microwave oven at $175{ }^{\circ} \mathrm{C} / 350 \mathrm{~W}$ in freshly distilled 2-(dimethylamino)ethanol (DMAE), ${ }^{25}$ in the presence of 1,8-diazabicyclo[5.4.0]undec-7-ene (DBU) and anhydrous $\mathrm{Cu}(\mathrm{OAc})_{2}$ or $\mathrm{Co}(\mathrm{OAc})_{2}$, the respective $\mathrm{Cu}$ and Co porphyrazines 11 and $\mathbf{1 2}$ were isolated in $67 \%$ and $72 \%$ yields, respectively. These two complexes show a good solubility in different classic organic solvents (e.g. $\mathrm{CH}_{2} \mathrm{Cl}_{2}, \mathrm{CHCl}_{3}$, THF, $\mathrm{Et}_{2} \mathrm{O}, \mathrm{MeOH}$ ).

Catalytic cyclopropanation. As benchmark catalysis test we opted for transition metal complex-mediated cyclopropanation of alkenes with diazo compounds, an efficient and selective method for access to synthetically and biologically interesting cyclopropanes. ${ }^{26} \mathrm{~A}$ huge amount of examples concerning the porphyrine metal complexes mediated cyclopropanation of alkenes are reported, ${ }^{27-29}$ while few examples of the use of phthalocyanine transition metal complexes 
have recently appeared. ${ }^{30-32}$ Some of us reported recently studies in cyclopropanation reactions by using transition metal complexes with nitrogen ligands. ${ }^{33,34}$

Table 1. Catalytic cyclopropanation of alkenes mediated by 11 and 12 in $\mathrm{CH}_{2} \mathrm{Cl}_{2}$ at $40{ }^{\circ} \mathrm{C}$. Yields and ratio were obtained by GC-MS and ${ }^{1} \mathrm{H}$ NMR using examethylbenzene as internal standard

Entry Substrate Catalyst

General procedure for catalytic cyclopropanation. Reactions are carried out by slow addition of a solution of ethyl diazoacetate (EDA) $\left(5.0 \mathrm{mmol}\right.$ in $10 \mathrm{~mL}$ of $\left.\mathrm{CH}_{2} \mathrm{Cl}_{2}\right)$ under stirring to a refluxing $\mathrm{CH}_{2} \mathrm{Cl}_{2}$ solution (75mL) consisting of alkene (12.5 mmol, $\left.0.2 \mathrm{M}\right)$ and 11 or $12(0.005$ mmol). Molar ratio catalyst / EDA / alkene $=1 / 1000 / 2500$. The reaction was monitored by IR till the complete consumption of EDA $\left[v_{\mathrm{N}=\mathrm{N}} 2110 \mathrm{~cm}^{-1}\right]$. Yields and diastereomeric ratio were obtained by GC-MS and ${ }^{1} \mathrm{H}$ NMR using examethylbenzene as internal standard.

Our aim was to test the efficacy of the metal-porphyrazine complexes $\mathbf{1 1}$ and $\mathbf{1 2}$ in activating the diazo precursor (i.e., EDA), via the metal carbenoid specie, to the cyclopropanation reaction of aromatic, aliphatic and carbonyl conjugated alkenes. In this contest we decide to run the catalytic tests (Table 1) with EDA as limitating reagent (ratio 
catalyst:EDA:substrate 1:1000:2500), the reactions were considered terminated when no trace of EDA was detected (IR) in the mixture. The reaction was monitored by GC-MS and ${ }^{1} \mathrm{H}$ NMR, it was related to maximum $\%$ of product formation respect to the quantity of diazo compound loaded into the reactor. The stereochemical trans:cis ratios of the cyclopropanes formed were also studied and reported in Table 1.

Good performances were obtained either from $\mathrm{Cu}(\mathrm{II})$ complex (11) (yield range 57-96 \%) and $\mathrm{Co}(\mathrm{II})$ complex (12) (yield range 53-95\%), even if the latter revealed a slower turnover frequency, in accordance with the data on phthalocyanine-catalyzed cyclopropanation previously reported by Zhou and coworkers. ${ }^{30}$ The reactions were run only once and the reported results are therefore unoptimized. The yields and the stereochemical outcomes of the reaction had proved to be substrate dependent, in fact the best result in cyclopropanation products were obtained with styrene (Table 1, entries 1 and 6) and the best trans selectivity emerged from the cyclopropanation of cyclohexenone (Table 1, entries 4 and 9).

\section{Experimental Section}

General. All reactions were performed using standard glassware and IKA num heating plates. Reactions utilizing air- and moisture-sensitive reagents were performed in dried glassware under an argon atmosphere. Solvents were used as received without further purifications, unless stated otherwise. All reagents, if not otherwise specified, were used as received and, if necessary, stored under inert gas. Oxcarbazepine was supplied by Trifarma SpA, Ceriano Laghetto, Italy. Silica thin-layer chromatography (TLC) was done on E. Merck plastic or aluminum-backed plates (silica gel 60, $\mathrm{F}_{254}, 0.2 \mathrm{~mm}$ ). Quantitative analyses of products were performed on a Shimadzu GC-17A gas chromatograph coupled with a QP5000 mass detector. Column chromatography was performed on E. Merck silica gel 60 (70-230 mesh). Microwave heating was performed on a CEM Discover SP instrument with a single-mode microwave cavity providing continuous irradiation at $2.45 \mathrm{GHz}$ and power up to $300 \mathrm{~W}$. Melting point determinations were performed by using a Gallenkamp melting point apparatus. ${ }^{1} \mathrm{H}$ NMR (400 $\mathrm{MHz})$ and ${ }^{13} \mathrm{C}$ NMR (100 MHz) were recorded on Bruker AV400 spectrometer; chemical shifts $(\delta)$ are expressed in parts per million (ppm) downfield from TMS $(\delta 0.0)$ and relative to the signal of $\mathrm{CDCl}_{3}$ (i.e., $\delta 7.26$ (singlet) and $\delta 77.0$ (triplet) for ${ }^{1} \mathrm{H} \mathrm{NMR}$ and ${ }^{13} \mathrm{C} \mathrm{NMR}$, respectively. Coupling constants are given in hertz $(\mathrm{Hz})$. Multiplicities were given as: s (singlet), $\mathrm{d}$ (doublet), $\mathrm{t}$ (triplet), dt (doublet of triplet), $\mathrm{m}$ (multiplet), br (broad). Infrared spectra were recorded in a Shimadzu Prestige 21 FTIR. UV-Vis spectra were obtained on a Thermo Scientific Evolution 220 instrument. MALDI-TOF-MS were recorded on Buker Multiflex LT spectrometer using $\alpha$-cyano-4-hydroxycinnamic acid (CHCA) as the matrix. Chemical ionization mass spectra $\left({ }^{+}\right.$ve mode) $\left(\mathrm{CI}^{+}\right.$-MS $)$were performed on a Finnigan-MAT TSQ70 with isobutane as the reactant gas. Elemental analyses were performed on a Perkin Elmer Series II CHNS/O Analyzer 2400; 
the samples were kept under vacuum $(0.001 \mathrm{hPa})$ at $60^{\circ} \mathrm{C}$ for $3 \mathrm{~h}$ before subsequent elemental analysis.

10,11-Dihydro-5-acetyl-5H-dibenzo $[\boldsymbol{b}, \boldsymbol{f}]$ azepine (7). A solution of 10,11 -dihydro-5Hdibenzo[ $b, f]$ azepine $5(2.50 \mathrm{~g}, 12.8 \mathrm{mmol})$ in acetic anhydride $(8 \mathrm{~mL})$ was refluxed for $3 \mathrm{~h}$ under stirring. The formation of the product was controlled via GC-MS. When the reaction was complete the mixture was dropped into water, extracted with AcOEt and dried in vacuo to give 7 $(2.88 \mathrm{~g}, 95 \%)$ as white solid. The spectroscopic data were in accordance with those reported in the literature. ${ }^{35}$

$\mathbf{5} \boldsymbol{H}$-Dibenzo $[\boldsymbol{b}, \boldsymbol{f}]$ azepine-10,11-dione (3). Oxcarbazepine $(\mathbf{2}, 5.0 \mathrm{~g}, 19.82 \mathrm{mmol})$ and $\mathrm{SeO}_{2}(5.4$ $\mathrm{g}, 48.67 \mathrm{mmol})$ in dioxane $(100 \mathrm{~mL})$ were brought to reflux under vigorous stirring for $7 \mathrm{~h}$. The reaction progress was monitored by TLC analysis $\left(\mathrm{SiO}_{2}, \mathrm{CH}_{2} \mathrm{Cl}_{2} / \mathrm{EtOH} 95: 5, R_{f} \mathbf{1}=0.27, R_{f} \mathbf{3}=\right.$ 0.56). After cooling to r.t. the orange precipitate was filtered and dried under vacuum to afford 3 $(4.0 \mathrm{~g}, 90 \%)$ : the spectroscopic data were in accordance with those reported in the literature. ${ }^{17}$

$\mathbf{5} \boldsymbol{H}$-Dibenzo $[\boldsymbol{b}, \boldsymbol{f}]$ azepine-10,11-dione (3). A suspension of 7 (300 $\mathrm{mg}, 1.26 \mathrm{mmol}$ ) and benzeneseleninic anhydride $(910 \mathrm{mg}, 2.52 \mathrm{mmol})$ in chlorobenzene $(5 \mathrm{~mL})$ was refluxed for $8 \mathrm{~h}$, under vigorous stirring. The precipitate was filtered, washed with chlorobenzene $(2 \mathrm{~mL}), \mathrm{Et}_{2} \mathrm{O}(4$ $\mathrm{mL}$ ) and dried in vacuum to afford $3(200 \mathrm{mg}, 68 \%)$. The spectroscopic data were in accordance with those reported in the literature. ${ }^{17}$

9H-Dibenzo[b,f]pyrazino[2,3- $d]$ azepine-2,3-dicarbonitrile (4). Compound 3 (100 mg, 0.45 mmol) and diaminomaleonitrile (49 $\mathrm{mg}, 0.45 \mathrm{mmol})$ in $\mathrm{AcOH}(2 \mathrm{~mL})$ were refluxed for $1 \mathrm{~h}$ under stirring. The reaction progress was monitored by TLC analysis $\left(\mathrm{SiO}_{2}, \mathrm{CH}_{2} \mathrm{Cl}_{2} / \mathrm{EtOH} 19: 1\right.$, $\mathrm{R}_{\mathrm{f}}$ 3: $0.54, \mathrm{R}_{\mathrm{f}}$ 4: 0.73). The reaction mixture was left cooling to r.t., the precipitate was collected by filtration and dried under vacuum to afford $4(86 \mathrm{mg}, 65 \%)$ as red solid. The spectroscopic data were in accordance with those reported in the literature. ${ }^{14}$

9-Hexadecanoyl-9H-dibenzo[b,f]pyrazino[2,3- $d]$ azepine-2,3-dicarbonitrile (9). A solution of $4(950 \mathrm{mg}, 3.22 \mathrm{mmol})$ and hexadecanoyl chloride $(1.51 \mathrm{~mL}, 5.0 \mathrm{mmol})$ in pyridine $(4 \mathrm{~mL})$ was stirred for $10 \mathrm{~min}$ at room temperature in the presence of 4- $N, N$-dimethylaminopyridine $(122 \mathrm{mg}$, $1.0 \mathrm{mmol}$ ) and then refluxed for $6 \mathrm{~h}$. The mixture was then poured into ice-water, acidified with $5 \% \mathrm{HCl}$ and extracted with AcOEt $(3 \times 50 \mathrm{~mL})$. The organic layers were dried $\left(\mathrm{Na}_{2} \mathrm{SO}_{4}\right)$ and the solvent was removed under reduced pressure. Column chromatography $\left(\mathrm{SiO}_{2}, \mathrm{CH}_{2} \mathrm{Cl}_{2}, \mathrm{R}_{f} 0.15\right)$ afforded $9(1.28 \mathrm{~g}, 75 \%)$ as a reddish glass. IR $(\mathrm{KBr}) \mathrm{cm}^{-1}: 2232(\mathrm{C} \equiv \mathrm{N}), 1670(\mathrm{C}=\mathrm{O}) ;{ }^{1} \mathrm{H}$ NMR $\left(400 \mathrm{MHz}, \mathrm{CDCl}_{3}\right): \delta 8.07(\mathrm{~d}, J 7.4 \mathrm{~Hz}, 2 \mathrm{H}), 7.72(\mathrm{~d}, J 7.4 \mathrm{~Hz}, 2 \mathrm{H}), 7.61-7.49(\mathrm{~m}, 4 \mathrm{H}), 2.25(\mathrm{t}, J$ $7.0 \mathrm{~Hz}, 2 \mathrm{H}), 1.70-1.20(\mathrm{~m}, 26 \mathrm{H}), 0.90(\mathrm{t}, J 7.0 \mathrm{~Hz} 3 \mathrm{H}) ;{ }^{13} \mathrm{C} \mathrm{NMR}\left(100 \mathrm{MHz}, \mathrm{CDCl}_{3}\right): \delta 173.1$, 144.5, 144.1, 133.6, 132.8, 132.4, 129.6, 128.9, 128.3, 113.4, 34.3, 34.2, 32.3, 30.1, 30.0, 30.0, 29.9, 29.8, 29.6, 29.5, 25.3, 25.1, 23.1, 14.5; MS (ESI): $\mathrm{m} / z 534\left([\mathrm{M}+\mathrm{H}]^{+}\right)$; Anal. Calcd. for $\mathrm{C}_{34} \mathrm{H}_{39} \mathrm{~N}_{5} \mathrm{O}: \mathrm{C}, 76.52 ; \mathrm{H}, 7.37$; N, 13.12. Found: C, 76.38; H, 7.45; N, 13.41.

Tetrakis-2,3-\{9-hexadecanoyl-9H-dibenzo $[b, f]$ pyrazino $[2,3-d]$ azepine $\}$ porphyrazinatomagn esium(II) (10). Magnesium (13 mg, $0.56 \mathrm{mmol}$ ), a small crystal of $\mathrm{I}_{2}$ and 1-butanol (5 mL) were heated to reflux under $\mathrm{N}_{2}$ for $6 \mathrm{~h}$. After the mixture was cooled to room temperature dinitrile 9 
(75 mg, $0.14 \mathrm{mmol}$ ) was added and the solution refluxed for further $8 \mathrm{~h}$. The reaction progress was monitored by TLC analysis $\left(\mathrm{SiO}_{2}, \mathrm{CH}_{2} \mathrm{Cl}_{2} / \mathrm{MeOH}\right.$ 19:1, $\left.\mathrm{R}_{f} \mathbf{1 0}: 0.28\right)$. After being allowed to cool to room temperature the dark green mixture was evaporated with toluene $(3 \times 5 \mathrm{~mL})$. The mixture was then dissolved in $\mathrm{CH}_{2} \mathrm{Cl}_{2}(5 \mathrm{~mL})$ and filtered through Celite. Evaporation of the solvent gave a green residue which was purified by flash column chromatography $\left(\mathrm{SiO}_{2}\right.$, $\left.\mathrm{CH}_{2} \mathrm{Cl}_{2} / \mathrm{MeOH} 19: 1\right)$ to afford $\mathbf{1 0}(24 \mathrm{mg}, 32 \%)$ as a green powder. $\mathrm{mp}>200{ }^{\circ} \mathrm{C}$; UV-Vis (THF, c $\left.1 \cdot 10^{-5} \mathrm{~mol} \mathrm{dm}^{-3}\right) \lambda_{\max }(\varepsilon): 376$ (70200), 598 (16600), 660 (132300) nm $\left(\mathrm{mol}^{-1} \mathrm{dm}^{3} \mathrm{~cm}^{-1}\right)$; IR $(\mathrm{KBr}) \mathrm{cm}^{-1}: 1668,1454,1350,1253,1182,1101,947,801,748 ;{ }^{1} \mathrm{H} \mathrm{NMR}\left(400 \mathrm{MHz}, \mathrm{CDCl}_{3}\right): \delta$ 8.25-7.42 (br, 32H), 2.45-2.23 (br, 8H), 1.70-0.75 (br, 116H); MS (MALDI-TOF): $\mathrm{m} / \mathrm{z} 2158.4$; Anal. Calcd. for $\mathrm{C}_{136} \mathrm{H}_{156} \mathrm{MgN}_{20} \mathrm{O}_{4}$ : C, 75.65; H, 7.28; N, 12.97. Found: C, 75.32; H, 7.57; N, 13.21.

Tetrakis-2,3-\{9-hexadecanoyl-9H-dibenzo $[b, f]$ pyrazino[2,3- $d]$ azepine $\}$ porphyrazinatocoppe r(II) (11). A mixture of dinitrile $9(200 \mathrm{mg}, 0.37 \mathrm{mmol})$ and anhydrous $\mathrm{Cu}(\mathrm{OAc})_{2}(33 \mathrm{mg}, 0.18$ $\mathrm{mmol}$ ) in freshly distilled 2-(dimethylamino)ethanol (DMAE) (5 $\mathrm{mL})$ and 1,8-diazabicyclo[5.4.0] undec-7-ene (DBU) $(0.5 \mathrm{~mL})$ was irradiated in a 10 -mL quartz vessel (equipped with a Teflon septum and a magnetic stir bar) by a microwave oven at $300 \mathrm{~W} / 175^{\circ} \mathrm{C}$ for $10 \mathrm{~min}$. After cooling to room temperature, the reaction mixture was diluted with water (5 $\mathrm{mL}$ ) and filtered off. The dark green product was purified by silica gel chromatography $\left(\mathrm{CH}_{2} \mathrm{Cl}_{2} / \mathrm{MeOH} 19: 1\right)$ to give $\mathbf{1 1}(138 \mathrm{mg}, 67 \%)$ as green powder. $\mathrm{mp}>200{ }^{\circ} \mathrm{C}$; UV-Vis $(\mathrm{THF}, \mathrm{c}$ $\left.1 \cdot 10^{-5} \mathrm{~mol} \mathrm{dm}^{-3}\right): \lambda_{\max }(\varepsilon) 378$ (62300), 599 (13200), 660 (115600) $\mathrm{nm}\left(\mathrm{mol}^{-1} \mathrm{dm}^{3} \mathrm{~cm}^{-1}\right)$; IR (KBr) $\mathrm{cm}^{-1}: 1671,1456,1347,1251,1184,1103,948,801,749$; MS (MALDI-TOF): $\mathrm{m} / \mathrm{z}$ 2197.3; Anal. Calcd. for $\mathrm{C}_{136} \mathrm{H}_{156} \mathrm{CuN}_{20} \mathrm{O}_{4}$ : C, 74.30; H, 7.15; N, 12.74. Found: C, 74.48; H, $7.26 ; \mathrm{N}, 12.97$.

Tetrakis-2,3-\{9-hexadecanoyl-9H-dibenzo $[b, f]$ pyrazino $[2,3-d]$ azepine $\}$ porphyrazinatocobalt (II) (12). A mixture of dinitrile 9 (200 mg, $0.37 \mathrm{mmol})$ and anhydrous $\mathrm{Co}(\mathrm{OAc})_{2}$ (33 mg, 0.19 mmol) in freshly distilled 2-(dimethylamino)ethanol (DMAE) (5 $\mathrm{mL})$ and 1,8-diazabicyclo[5.4.0] undec-7-ene (DBU) $(0.5 \mathrm{~mL})$ was irradiated in a $10-\mathrm{mL}$ quartz vessel (equipped with a Teflon septum and a magnetic stir bar) by a microwave oven at $300 \mathrm{~W} / 175^{\circ} \mathrm{C}$ for $10 \mathrm{~min}$. After cooling to room temperature, the reaction mixture was diluted with water (5 $\mathrm{mL}$ ) and filtered off. The dark green product was purified by silica gel chromatography $\left(\mathrm{CH}_{2} \mathrm{Cl}_{2} / \mathrm{MeOH} 19: 1\right)$ to give $12(148 \mathrm{mg}, 72 \%)$ as dark green powder. mp $>200{ }^{\circ} \mathrm{C}$; $\mathrm{UV}-\mathrm{Vis}$ (THF, c $\left.1 \cdot 10^{-5} \mathrm{~mol} \mathrm{dm}{ }^{-3}\right): \lambda_{\max }(\varepsilon) 377$ (63500), 597 (13600), 658 (118300) nm $\left(\mathrm{mol}^{-1} \mathrm{dm}^{3} \mathrm{~cm}^{-1}\right)$; IR (KBr) cm ${ }^{-1}: 1670,1455,1350,1253,1183,1099,949,802,748$; MS (MALDI-TOF): $\mathrm{m} / \mathrm{z}$ 2193.4; Anal. Calcd. for $\mathrm{C}_{136} \mathrm{H}_{156} \mathrm{CoN}_{20} \mathrm{O}_{4}$ : C, 74.46; H, 7.17; N, 12.77. Found: C, 74.39; H, 7.33; N, 13.06 .

X-ray Crystallographic Analysis. Crystals of suitable quality of compound $\mathbf{8}\left(\mathrm{C}_{16} \mathrm{H}_{11} \mathrm{NO}_{2}\right)$ were obtained by slow evaporation of an EtOH solution. Diffraction data were collected at r.t. on a Enraf Nonius CAD4 diffractometer with graphite-monochromatized Mo-K $\alpha$ radiation ( $\lambda$ $0.71073 \AA$ A). Generator settings: $50 \mathrm{kV}, 30 \mathrm{~mA}$ ). Lorentz-polarization correction was applied. The structure was solved by direct methods (SIR92) ${ }^{36}$ and expanded using Fourier techniques 
(SHELX97). ${ }^{37}$ Non-hydrogen atoms were refined anisotropically. Hydrogen atoms were included in the final model and freely refined. The final cycles of full-matrix least-squares refinements were based on $\mathrm{F}^{2}$. All calculations were performed using the WINGX Crystallographic Software Suite. ${ }^{38}$ CCDC deposition number 987293. An ORTEP drawing of the molecule of $\mathbf{8}$ is shown in Figure 1. Copies of the data can be obtained free of charge via http://www.ccdc.cam.ac.uk/conts/retrieving.html (or from the Cambridge Crystallographic Data Centre, 12, Union Road, Cambridge, CB2 1EZ, UK; Fax: p44 1223 336033; e-mail: deposit@ccdc.cam.ac.uk).

Crystal data for Compound 8: $\mathrm{C}_{16} \mathrm{H}_{11} \mathrm{NO}_{2}$, f.w. $=249.26 \mathrm{gmol}^{-1}, 293 \mathrm{~K}, \lambda=0.71073 \AA$, monoclinic, space group $\mathrm{P} 21 / \mathrm{n}, a=7.350(2), b=20.834(3), c=8.576(3) \AA, \beta=114.51(2)^{\circ}, \mathrm{V}=$ 1194.9(6) $\AA^{3}, \mathrm{Z}=4, \rho_{\text {calc }}=1.386 \mathrm{~g} \mathrm{~cm}^{-3}, \mu(\mathrm{Cu} \mathrm{K \alpha})=0.092 \mathrm{~mm}^{-1}, \mathrm{R} 1=0.0437$ for 1518 observed reflections with $\mathrm{Fo}>4 \sigma(\mathrm{Fo}), \mathrm{wR} 2=0.1047$ for all 2165 reflections; Gof $=1.030,2 \theta$ range: $3-25.3^{\circ}$.

General procedure for catalytic cyclopropanation. A solution of ethyl diazoacetate (EDA) (5.0 mmol in $10 \mathrm{~mL}$ of $\mathrm{CH}_{2} \mathrm{Cl}_{2}$ ) was added slowly under stirring to a refluxing $\mathrm{CH}_{2} \mathrm{Cl}_{2}$ solution $(0.2 \mathrm{M})$ consisting of alkene $(12.5 \mathrm{mmol})$ and 11 or $12(0.005 \mathrm{mmol})$. The reaction was halted when no trace of EDA $\left[v_{\mathrm{N}=\mathrm{N}} 2110 \mathrm{~cm}^{-1}\right]$ was detected in the IR spectrum of the mixture. Yields and diastereomeric ratio were obtained by GC-MS and ${ }^{1} \mathrm{H}$ NMR using examethylbenzene as internal standard.

\section{Acknowledgements}

We are grateful to Trifarma SpA, Ceriano Laghetto, Italy for supplying us with a generous loan of oxcarbazepine. We would also like to thank Professor S. Tollari (Dipartimento di Scienza e Alta Tecnologia, Università degli Studi dell'Insubria) for his many fine and insightful suggestions.

\section{References}

1. Moser, F. H.; Thomas, L. R. In Phthalocyanine compounds; Reinhold, New York, 1963.

2. Leznoff, C. C.; Lever A. B. P. In Phthalocyanines, Properties and Applications, 4 Volumes Set; VCH: New York, 1998.

3. Raymond, B. Chem. Soc. Rev. 1995, 24, 19.

http://dx.doi.org/10.1039/cs9952400019

4. Chu, J.-H.; Kosal, M. E.; Nalwa, H. S.; Rakow, N. A.; Suslick, K. S. in The Porphyrins Handbook; Kadish, K. M.; Smith, K. M.; Guillard, R. Eds.; Academic Press: San Diego, 2000; Vol. 6, pp 44-128. 
5. Sorokin, A. B. Chem. Rev. 2013, 113, 8152.

http://dx.doi.org/10.1039/cs9952400019

6. Angeloni, S.; Ercolani, C. J. Porphyrins Phthalocyanines 2000, 4, 474 and references cited therein.

http://dx.doi.org/10.1002/1099-1409(200008)4:5<474::AID-JPP276>3.0.CO;2-W

7. Zhang, Z.; Zhang, M.; Deng, J.; Deng, K.; Zhang, B.; Lv, K.; Sun, J.; Chen, L. Applied Catalysis B: Environmental 2013, 132-133, 90.

http://dx.doi.org/10.1016/j.apcatb.2012.11.027

8. Nemykin, V. N.; Lukyanets, E. A. Arkivoc 2010, (i), 136.

http://dx.doi.org/10.3998/ark.5550190.0011.104

9. McKeown, N. B. in The Porphyrins Handbook; Kadish, K. M.; Smith, K. M.; Guillard, R. Eds.; Academic Press: San Diego, 2003; Vol.15, pp 61-116.

http://dx.doi.org/10.1016/B978-0-08-092389-5.50008-0

10. Heckendorn, R. Helv. Chim. Acta 1987, 70, 1955.

http://dx.doi.org/10.1002/hlca.19870700730

11. Riley, H. L.; Morley, J. F.; Friend, N. A. C. J. Chem. Soc. 1932, 1875. http://dx.doi.org/10.1039/jr9320001875

12. Park, B. S.; Lee, H. M.; Cho, S. Bull. Korean Chem. Soc. 2007, 28, 871 and references cited therein.

http://dx.doi.org/10.5012/bkcs.2007.28.5.871

13. For a review on selenium-promoted oxidation of organic compounds, see: Młochowski, J.; Brzaszcz, M.; Giurg, M.; Palus, J.; Wojtowicz, H. Eur. J. Org. Chem. 2003, 4329. http://dx.doi.org/10.1002/ejoc.200300230

14. Vaghi, L.; Gaudino, E. C.; Cravotto, G.; Palmisano, G.; Penoni, A. Molecules 2013, 18, 13705. http://dx.doi.org/10.3390/molecules181113705

15. Sosnovsky, G.; Krogh, J. A. Synthesis 1978, 703. http://dx.doi.org/10.1055/s-1978-2486

16. Sosnovsky, G.; Krogh, J. A.; Umhofer, S. G. Synthesis 1979, 722. http://dx.doi.org/10.1055/s-1979-28813

17. Chen, C. .T.; Lin, J. S.; Moturu M. V. R. K.; Lin, Y. W.; Yi, W.; Tao, Y. T.; Chien, C. H. Chem. Commun. 2005, 3980. http://dx.doi.org/10.1039/b506409k

18. Renfroe, B.; Harrington, C.; Proctor, G. R. In Chemistry of Heterocyclic Compounds; Rosowsky, A. Ed.; John Wiley \& Sons, 1984; Vol. 43.

19. Allukian, M.; Fry, A. J.; Williams, A. D. Tetrahedron 2002, 58, 4411. http://dx.doi.org/10.1016/S0040-4020(02)00415-5

20. Furst, S. M.; Sukhai, P.; McClelland, R. A.; Uetrecht, J. P. Drug. Metab. Dispos. 1995, 23, 590. 
21. Singh, H.; Gupta, N.; Kumar, P.; Dubey, S. K.; Sharma, P. K. Org. Proc. Res. Develop. 2009, 13, 870 . http://dx.doi.org/10.1021/op900127v

22. Clayton, M. D.; Marcinow, Z.; Rabideau, P. W. Tetrahedron Lett. 1998, 39, 9127. http://dx.doi.org/10.1016/S0040-4039(98)02063-2

23. Hess, B. A.; Boekelheide, V. J. Am. Chem. Soc. 1969, 91, 1672. http://dx.doi.org/10.1021/ja01035a014

24. Linstead, R. P.; Whalley, M. J. Chem. Soc. 1952, 4839. http://dx.doi.org/10.1039/jr9520004839

25. Kahveci, B.; Saşmaz, S.; Özil, M.; Kantar, C.; Koşar, B.; Büyükgüngör, O. Turk. J. Chem. 2006, 30, 681.

26. Lebel, H.; Marcoux, J.-F.; Molinaro, C.; Charette, A. B. Chem. Rev. 2003, 103, 977. http://dx.doi.org/10.1021/cr010007e

27. Intrieri, D.; Caselli, A.; Gallo, E. Eur. J. Inorg. Chem. 2011, 5071. http://dx.doi.org/10.1002/ejic.201100664

28. Che, C.-M.; Huang, J.-S. Coord. Chem. Rev. 2002, 231, 151. http://dx.doi.org/10.1016/S0010-8545(02)00117-0

29. Simonneaux, G.; Le Maux, P.; Ferrand, Y.; Rault-Berthelot, J. Coord. Chem. Rev. 2006, 250, 2212. http://dx.doi.org/10.1016/S0010-8545(02)00117-0

30. Liu, H.-H.; Wang, Y.; Shu, Y.-J.; Zhou, X.-G.; Wu, J.; Yan, S.-Y. J. Mol. Catal. A: Chem. 2006, 246, 49. http://dx.doi.org/10.1016/j.molcata.2005.10.014

31. Sharma, V. B.; Jain, S. L.; Sain, B. Catal. Commun. 2006, 7, 454. http://dx.doi.org/10.1016/j.catcom.2005.12.027

32. Fields, K. B.; Engle, J. T.; Sripothongnak, S.; Kim, C.; Zhang, X. P.; Ziegler, C. J. Chem. Commun. 2011, 47, 749. http://dx.doi.org/10.1039/c0cc03894f

33. Penoni, A.; Wanke, R.; Tollari, S.; Gallo, E.; Musella, D.; Ragaini, F.; Demartin, F.; Cenini, S. Eur. J. Inorg. Chem. 2003, 1452. http://dx.doi.org/10.1002/ejic.200390189

34. Maspero, A.; Brenna, S.; Galli, S.; Penoni, A. J. Organomet. Chem. 2003, 672, 123. http://dx.doi.org/10.1016/S0022-328X(03)00132-3

35. Csende, F.; Hosztafi, S. J. Prakt. Chem. 1997, 339, 587. http://dx.doi.org/10.1002/prac.199733901104

36. Altomare, A.; Cascarano, G.; Giacovazzo, C.; Guagliardi, A.; Burla, M. C.; Polidori, G.; Camalli, M. J. Appl. Cryst. 1994, 27, 435. http://dx.doi.org/10.1107/S002188989400021X

37. Sheldrick, G. M. Acta. Cryst. 2008, A64, 112. http://dx.doi.org/10.1107/S0108767307043930 
38. Farrugia, L. J. J. Appl. Cryst. 1999, 32, 837.

http://dx.doi.org/10.1107/S0021889899006020 